\title{
Effect of Static and Dynamic Stretching on Knee Muscle Strength in Trained Players
}

\section{Antrenmanlı Sporcularda Statik ve Dinamik Germe Egzersizlerinin Diz Kas Gücü Üzerine Etkisi}

\section{(D) Chasan Mola Ali1, (D Filiz Tuna², (D) Hasan Kerem Alptekin³, (D Derya Demirbağ Kabayel4, (D Hakan Tuna 4}

1Yeni Yüzyll University Faculty of Medicine, Department of Physical Therapy, İstanbul, Turkey

2Trakya University, Health Sciences Institute Physiotherapy and Rehabilitation, Edirne, Turkey

${ }^{3}$ Bahçeşehir University, Health Sciences Institute Physiotherapy and Rehabilitation, İstanbul, Turkey

${ }^{4}$ Trakya University Faculty of Health Sciences, Department of Physiotherapy, Edirne, Turkey

\section{Abstract}

Objective: The study examined the effects of two different stretching exercises on knee muscle strength in basketball players in order to determine the most appropriate pre-competition protocols for basketball conditioning.

Method: Thirty-two basketball players (mean age 22.75 \pm 2.73 years, weight $87.47 \pm 10.99 \mathrm{~kg}$, height $188.85 \pm 7.35 \mathrm{~cm}$, body mass index $24.46 \pm 1.89)$ participated in this study. They performed two different stretching protocols according to basketball training experience in randomly assigned order: randomized in consecutive manner according to admission order, well-trained basketball players (training frequency = 5 days/week, groups I and II), less-trained basketball players (1 day/week, groups III and IV). Basketball players in groups I and III were exposed to isokinetic tests-one each after dynamic stretching and, 1 week later, after static stretching. In groups II and IV, similar evaluations were made after static stretching and, 1 week later, after dynamic stretching. Five days/ week were included in the well-trained group. The less-trained group consisted of basketball players who trained 1 day/week.

Results: In less-trained basketball players, static stretching resulted in higher extensor muscular strength and endurance values, whereas dynamic stretching increased knee flexor strength and endurance.

Conclusion: Our results suggest that before competitions, stretching exercises should be chosen depending on the conditioning of the basketball player (well-trained, less-trained). Including both static and dynamic stretching into the "stretching" concept seems effective.

\section{Öz}

\begin{abstract}
Amaç: Bu çalışmanın amacı, basketbol oyuncularında fiziksel dayanıklılı̆ı artırmak için müsabaka öncesi en uygun protokolün belirlenmesinde iki farklı germe egzersizinin etkilerini incelemektir.
\end{abstract}

Yöntem: Bu çalışmada, 32 basketbol oyuncusu (ortalama yaş 22,75 $\pm 2,73$, kilo $87,47 \pm 10,99 \mathrm{~kg}$, boy $188,85 \pm 7,35 \mathrm{~cm}$, vücut kitle indeksi $24,46 \pm 1,89$ ) yer almıştır. Basketbol oyuncuları antrenman deneyimlerine göre iki farklı germe egzersizi yapmak üzere randomize olarak gruplara ayrılmıştır: ardışık rastgele seçim yapılarak iyi antrenmanlı basketbol oyuncuları (antrenman sayısı =5 gün/hafta, grup I ve II), kötü antrenmanlı basketbol oyuncuları (1 gün/hafta, grup III ve IV). Grup I ve III için dinamik germe, ardından bir hafta sonra statik germe, grup II ve IV için statik germe, ardından bir hafta sonra dinamik germe egzersizleri sonrası izokinetik test uygulanmıştır.

Bulgular: Düşük-idmanlı basketbol oyuncularında, statik germe egzersizleri, daha yüksek ekstansör kas gücü ve dayanıklılık verileri gösterirken, dinamik germe, diz fleksör gücü ve dayanıklılığını artırmıştır.

Sonuç: Bulgularımız, basketbol oyuncularında antrenman durumuna göre (iyi antrenmanlı, kötü antrenmanlı) germe egzersizlerinin seçilmesini önermektedir. Hem statik hem de dinamik germe egzersizleri etkili bulunmuştur.

Anahtar kelimeler: Dinamik germe, izokinetik test, statik germe

Keywords: Dynamic stretching, isokinetic test, static stretching

Address for Correspondence: Chasan Mola Ali, Yeni Yüzyll University Faculty of Medicine, Department of Physical Therapy, İstanbul, Turkey E-mail: hasanmollaali@hotmail.com ORCID: orcid.org/0000-0001-5730-5620 Received: 09.05.2020 Accepted: 05.08.2020

Cite this article as: Ali CM, Tuna F, Alptekin HK, Demirbağ Kabayel D, Tuna H. Effect of Static and Dynamic Stretching on Knee Muscle Strength in Trained Players. Bagcilar Med Bull 2020;5(3):107-115

๑C Copyright 2020 by the Health Sciences University Turkey, Bagcilar Training and Research Hospital Bagcilar Medical Bulletin published by Galenos Publishing House. 


\section{Introduction}

Physical training is an important part of basketball performances (1). Stretching applied during the warm-up period increases the energy absorbent capacity of muscles, thus decreasing injury risk. In addition, it prepares the body for upcoming physical activity. Thus, stretching exercises are a part of athletes' pre-competition warm-up protocols $(2,3)$.

Flexibility is a component of physical fitness that athletes desire to develop. Static and dynamic-stretching exercises are among the methods that bring flexibility. Static stretching (SS) is defined as stretching where the athletes stay in a stretching position for a certain period (4). Dynamic stretching (DS), on the other hand, consists of slow-paced dynamic movements that are similar to upcoming actual physical activity (5).

Muscle strength is one of very important sports components for preventing injury and enhancing performance. Isokinetic dynamometers are very useful to evaluate muscle strength. These dynamometers determine the muscle balance and forces between the dominant and nondominant extremities as well as the agonist and antagonist muscles. Today, isokinetic devices are used for muscle rehabilitation and muscle training (6).

Isokinetic testing provides an objective quantitative measure for muscle functions. It also provides results on such parameters as muscle work, power, and endurance. With these objective parameters, it is possible to follow the progress of athletes or patients during rehabilitation periods and competitive performances (7).

Pre-competition warm-up, which has become a traditional practice, has limited scientific evidence to support its importance. Warm-up protocols usually reflect personal experiences of coaches, instructors and athletes. Previous studies have supported the positive effects of stretching exercises using static, dynamic or proprioceptive neuromuscular facilitation stretching techniques on increasing the joint mobility. Moreover, previous studies have also suggested that these positive effects include reduction in muscle injuries and improvement of sports performance (8). In this study, isokinetic tests were performed by basketball players after following SS and DS exercises, with a view of establishing their advantages and weaknesses. The aim of the study was to determine the most appropiate pre-competition exercise protocols for basketball players.

\section{Materials and Methods}

A quantitative, cross-sectional, and prospective study was conducted between 11.12.2013 and 11.06.2014 with the approval of the Ethics Committee of Trakya University Faculty of Medicine (protocol number: TÜTF-GOKAEK 2013/185) and the written informed consent was obtained from all participants.

Thirty-two male basketball players who met the eligibility criteria and committed to participate were included in this study. The eligibility criteria of the study were as following: having been involved in basketball for $\geq 5$ years, male gender, age of 18-30 years, absence of inflammatory or infectious joint pathology, commitment to participate in the study, absence of previous knee surgery, and absence of neurological disease affecting knee joint innervation.

Exclusion criteria of the study were as following: a history of cardiovascular or pulmonary disease that might hamper exercise, an inflammatory or infectious pathology of the knee joint, uncontrolled endocrine pathology, significant system or organ failure, neurological disease affecting the kneejoint innervation, and previous knee surgery. Basketball players who met the eligibility criteria and committed to participate in the study were examined according to their ages, height, weight, and dominant extremities.

Thirty-two basketball players included in the study were classified in two groups according to their training frequencies (Figure 1). Basketball players who trained 5 days/week were included in the well-trained group. The less-trained group consisted of basketball players who trained 1 day/week. Well-trained basketball players were randomized into groups I and II, and less-trained basketball players were randomized into groups III and IV. Basketball players in groups I and III were applied two isokinetic tests, one after DS and, 1 week later, the other after SS. Basketball players in group II and IV were subjected to the same evaluation following SS and, 1 week later, after DS, respectively.

All basketball players performed stretching exercises after cycling for $7 \mathrm{~min}$, which was at a speed of 80-90 revolution per minute (rpm) in the bicycle ergometer.

Dynamic Exercise Group: First, basketball players performed DS exercises after warming up in the bicycle ergometer at 80-90 rpm for $7 \mathrm{~min}$. In dynamic exercises, movements lasted for $15 \mathrm{~s}$ each, to be repeated after resting for 20-s (Table 1). DS exercises practiced by basketball players were as follows (Figure 2): 


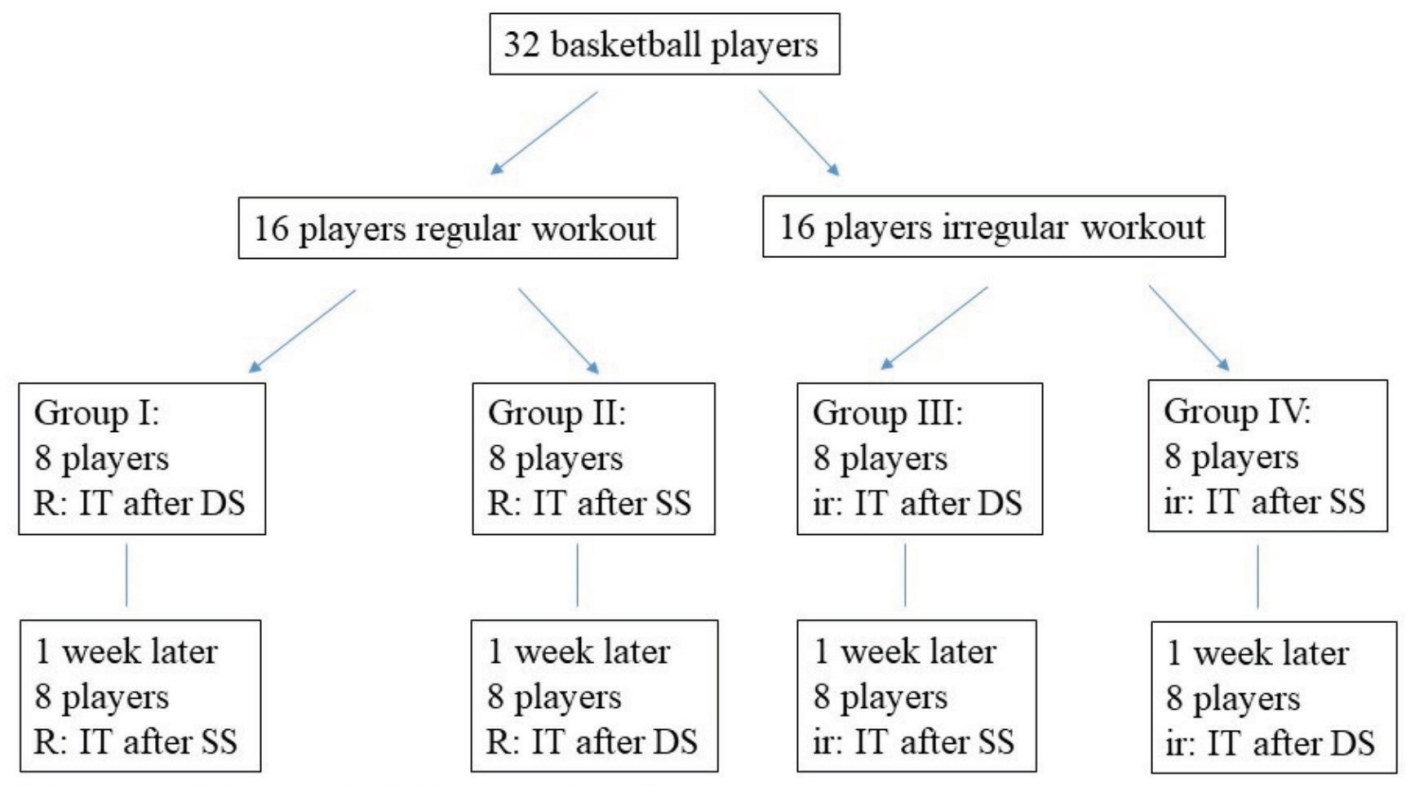

Figure 1. Experimental design

IT: Isokinetic test, SS: Static stretching, DS: Dynamic stretching, R: Regular, ir: Irregular

Table 1. Duration of stretching exercises applied to right and left extremity muscles

\begin{tabular}{lll} 
Muscles & $\begin{array}{l}\text { Dynamic-stretching } \\
\text { exercises }\end{array}$ & $\begin{array}{l}\text { Static-stretching } \\
\text { exercises }\end{array}$ \\
\hline Hamstring & $75 \mathrm{~s}$ & $80 \mathrm{~s}$ \\
Quadriceps & $45 \mathrm{~s}$ & $40 \mathrm{~s}$ \\
Adductors & $60 \mathrm{~s}$ & $40 \mathrm{~s}$ \\
Hip extensors & $45 \mathrm{~s}$ & $20 \mathrm{~s}$ \\
Hip flexors & $15 \mathrm{~s}$ & $20 \mathrm{~s}$ \\
Gastrocnemius & $75 \mathrm{~s}$ & $80 \mathrm{~s}$ \\
\hline
\end{tabular}

s: Second

DS exercise 1- Basketball players assumed a supine position with their upper limbs by the side of the body and their forearms supinated. When they performed cycling exercises, they flexed their hips and knees such that the knees touched their hands in a rhythmical pattern. This exercise stretches the hip extensors and hamstring muscles (Figure 2-1).

DS exercise 2- Basketball players' lower limbs were semiflexed, their shoulders were abducted to $70^{\circ}$, and their forearms were externally rotated with the palms facing up. Movements were repeated rhythmically along the line (right and left, then to the left). This exercise stretches adductor, quadriceps and gastrocnemius muscles (Figure 2-2).

DS exercise 3- From a standing position, basketball players raised one lower limb forward to flex the hip and knee to $90^{\circ}$ flexion, and then brought the limb back to the floor by hyperextending the hips and knees. Then, they moved the same lower limb forward by stepping rhythmically and flex the other lower limb such that the knee touched the floor while the hip was in hyperextension. This exercise stretches hip flexors, quadriceps, hip extensors, hamstring and gastrocnemius muscles (Figure 2-3).

DS exercise 4- While standing, basketball players abducted their hips to at least $50^{\circ}$ abduction. One lower limb was flexed to $90^{\circ}$ flexion at the knee and hip; the BW was transferred to that side and the adductor muscles of that side were stretched; during this, the other lower limb was in full extension. The trunk was then rotated $180^{\circ}$ while the same position was maintained. Then, the lower limb in full extension was flexed to at $90^{\circ}$ hip and knee flexion. This exercise stretches adductor muscles, while the other lower limb is in full extension (Figure 2-4).

DS exercise 5- While the basketball players were standing, one upper limb was flexed at the shoulder to $180^{\circ}$ flexion while the knee of the opposite side was flexed to $90^{\circ}$ flexion (right upper limb and left lower limb; then the left upper limb and the right lower limb). These movements were repeated rhythmically. This exercise stretches hip extensors and hamstring muscles (Figure 2-5).

DS exercise 6- Basketball players attempted to rhythmically touch the toes with the contralateral hands while they were walking. During this movement, the elbow was extended and shoulder was abducted, whereas the lower limb was 
in maximum flexion. This exercise stretches hamstring and gastrocnemius muscles (Figure 2-6).

DS exercise 7- Basketball players were standing with their shoulders at $90^{\circ}$ flexion and the elbow and wrist in full extension; then, they placed their palms on the wall. Basketball players transferred their weights to one of their lower limbs and they put the other lower limb forward. This lower limb was placed in maximum adduction and maximum abduction positions for $15 \mathrm{~s}$ each. The same movements were repeated for the other lower limb. This exercise stretches adductor muscles (Figure 2-7).

DS exercise 8- Basketball players were standing with their knees at full extension while hips were at full flexion; then hip extension repeated rhythmically in 15 seconds. The same exercise was repeated for the other side. This exercise stretches hamstring and gastrocnemius muscles (Figure 2-8).

Static Exercise Group: Basketball players warmed up on the bicycle ergometer for $7 \mathrm{~min}$ at $80-90 \mathrm{rpm}$ speed. Then, they performed static-stretching exercises consisting of
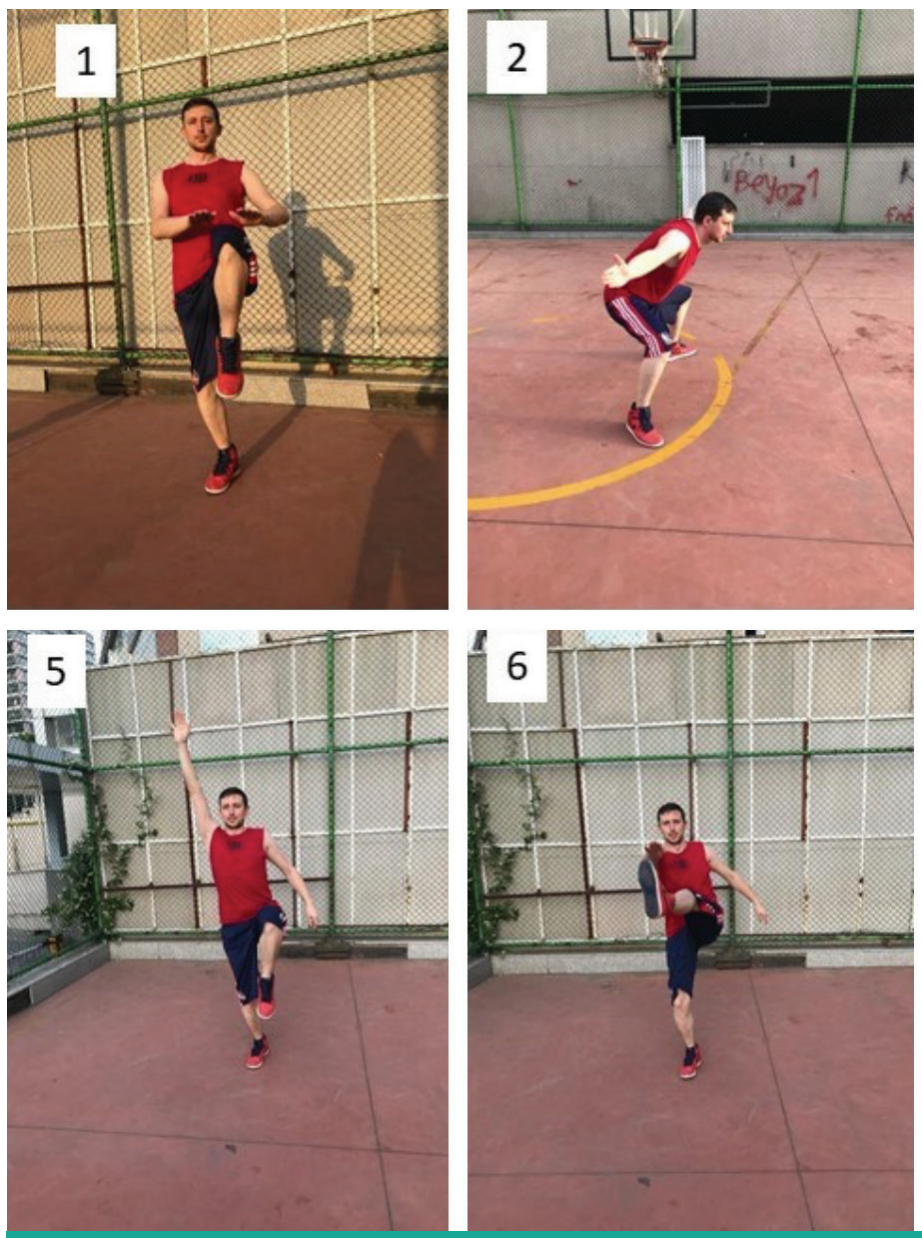

six movements. Five of the static exercises were repeated for $20 \mathrm{~s}$ for one extremity, and the same movement was repeated for the other extremities. They rested for 15 $s$ and moved to the other movement. One of the static exercises was directed to both limbs and the exercise lasted $20 \mathrm{~s}$. The exercise was repeated after resting for 15 s (Table 1).

Static-stretching exercises (Figure 3) were as follows:

SS exercise 1- While the basketball players were standing, they positioned both their lower limbs at a minimum $50^{\circ}$ abduction at the hip. On one side, they positioned the knee and the hip to $90^{\circ}$ flexion. Then, the body weight (BW) was transferred to that side, and the abductor muscles were stretched while the other lower limb was in full extension. The same exercise was repeated for the other side (Figure 3-1).

SS exercise 2- Basketball players moved one of their lower limbs forward, with the knee and the hip at $90^{\circ}$ flexion, and then, placed the other lower with the hip in hyperextension. The same exercise was repeated for the other side. This
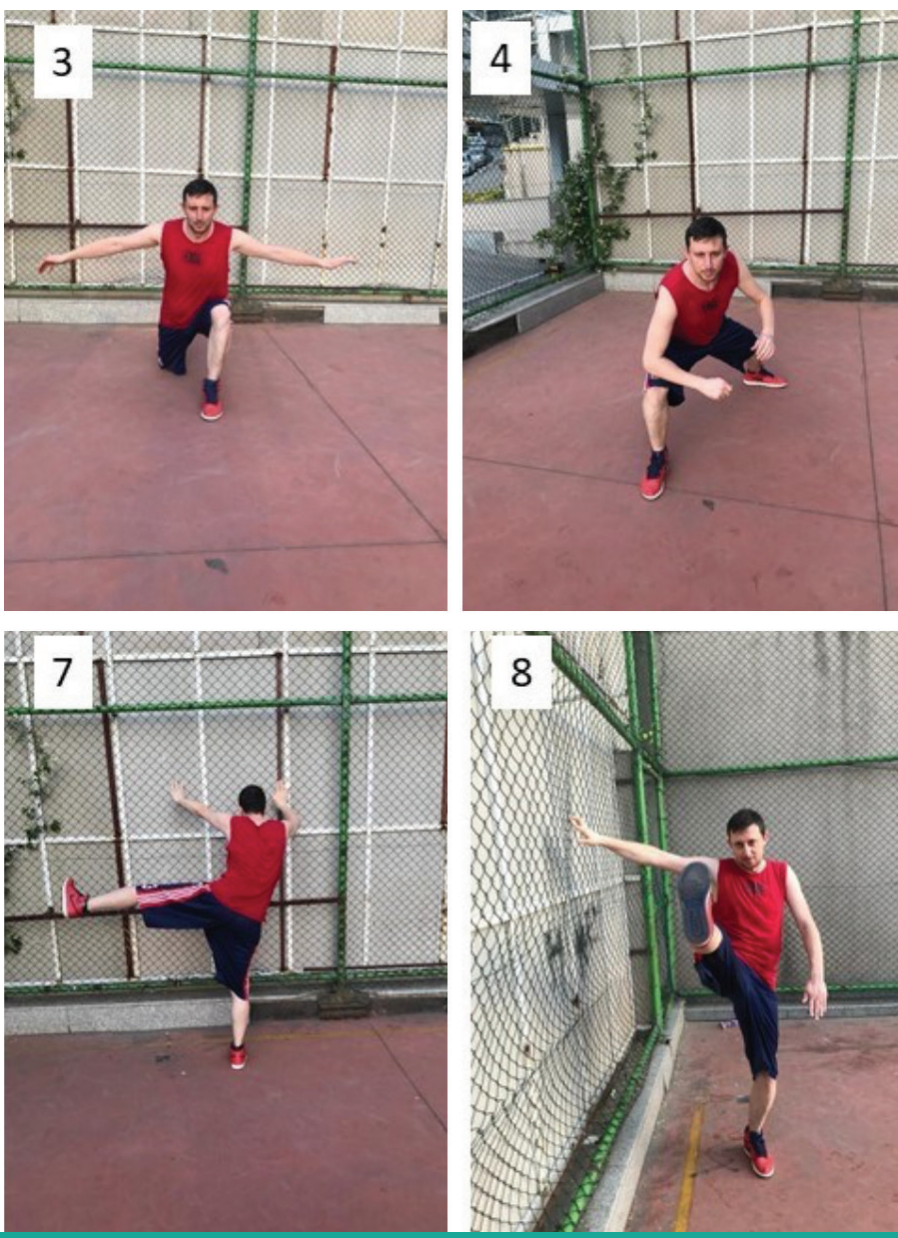

Figure 2. Dynamic stretching exercises applied to basketball players 
exercise stretches hip flexors, quadriceps, hip extensors and hamstring muscles (Figure 3-2).

SS exercise 3- While basketball players were sitting with their backs straight, both lower limbs were stretched out with the hips at maximum abduction. While the lowerlimb tension was maintained, the trunk was laterally flexed to make contact with one of the thighs, and the basketball players tried to touch their toes. The exercise was repeated on the other side. This exercise stretches adductor, hamstring and gastrocnemius muscles (Figure $3)$.

SS exercise 4- Both the lower limbs were stretched and positioned perpendicular to the other. The trunk was brought to touch the thighs while the tension of lower limbs was maintained. This exercise stretches hamstring and gastrocnemius muscles (Figure 3-4).

SS exercise 5- Basketball players stood standing while using support with one hand for balance. With the help of the other hand, the contralateral lower limb was flexed backward to the hip level. The same process was repeated for the other side. This exercise stretches the quadriceps muscle (Figure 3-5).
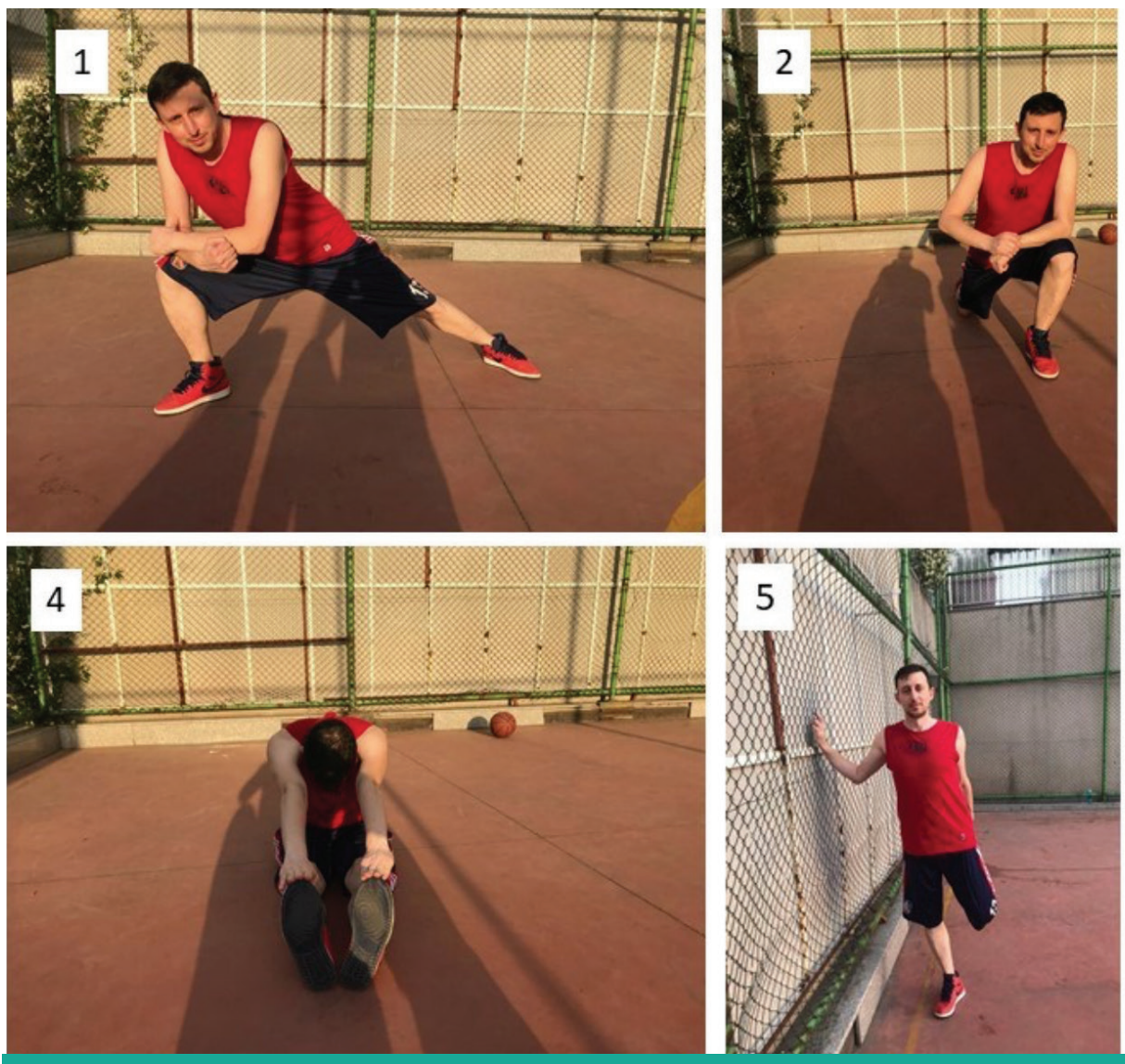

Figure 3. Static stretching exercises applied to basketball players
SS exercise 6- Basketball players stood two feet away from the wall. While one lower limb was stretched, the opposite lower limb was twisted one step forward and both hands were placed on wall for balance. During this stretching exercise, attention was on the heels' not being raised from the floor. The same process was repeated for the other side. The gastrocnemius muscles in both the extremities were stretched (Figure 3-6).

\section{Isokinetic Evaluation}

CSMI Cybex HUMAC NORM (model number 502.140 with isokinetic tests and exercise systems) was used for isokinetic evaluation. The device was calibrated before each test. The protocol for knee flexion and extension isokinetic muscle strength and endurance measurements were as following: Submaximal four trials at $60^{\circ} / \mathrm{s}$ angular velocity, and 6-s rest, four tests at maximum force and 20-s rest. Submaximal four trials at $240 \%$ s angular velocity, and 6-s rest, 20 tests at maximum force and termination of test. Before the test, the basketball players were informed regarding the purpose of this study, devices and the application; they also received motivational instructions during the test. Values of peak torque (PT), \% BW, total work (TW) and TW \% BW were 
recorded (9). PT value: It is the highest torque value among all test parameters obtained in the full range of motion in each full-joint movement at angular velocity. Among all test parameters, it is accepted as the gold standard in terms of accuracy, precision and reliability. Its measure is Newton meter.

PT\% BW: It is important to compare the test results among individuals and to evaluate the functional strength of the muscles that hold the weight. TW: It is the distance a force moves a certain resistance. Power: The amount of work done in time unit. Its unit is Watt. The endurance is the measurement of the fatigue developed in the muscle $(10,11)$. The low PT \% BW emphasizes the need for more strength training, a low TW value reflects lack of endurance and need of high repetition training. Moreover, low average power values highlight that power-based exercises should be applied (12).

\section{Statistical Analysis}

The data obtained from the study were saved in computer files. IBM Statistical Package for Social Sciences (SPSS) Statistics version 22 was used for statistical analyses (license number: 10240642). All parameters were normally distributed (Kolmogorov-Smirnov test). For group comparisons, OneWay ANOVA test and the paired sample t-test were used. The level of significance was set at $\mathrm{p}$ values of $<0.05$.

\section{Results}

Mean age, weight, and body mass index values of the groups are provided in Table 2 . The mean age of all basketball players was $22.75 \pm 2.73(18-28)$ years. The mean age was lower in group II than in group III $(\mathrm{p}=0.017)$. The mean height was higher in group I than in group IV ( $p=0.049)$. There were no other differences among the groups. The groups with no difference between the weight and body mass index averages were suitable for comparison $(p>0.05)$ (Table 2).

\section{Results of the First Evaluation}

The mean values of right knee extensor PT (EPT), flexor peak torque (FPT), extensor TW (ETW), flexor total work
(FTW); left knee FPT, ETW, ETW \% BW and FTW \% in group I (R: IT after DS) were significantly higher than those in group IV. The mean values of right knee EPT was higher in group 1 than in group III. The mean values for EPT \% BW in group II (R: IT after SS) were higher than those in group iii and group IV (Ir: IT after SS). In the first measurements in the right knees, group III had lower mean FTW\% BW than group I and group II. These differences were statistically significant $(\mathrm{p} \leq 0.05)$. There were no other statistically significant differences among the groups (Tables 3 and 4).

\section{Results of the Evaluation Made 1 Week after}

The mean values for right knee EPT and left knee ETW \% BW in group IV were lower than those in groups I and II. The mean values for right knee EPT, FPT and ETW as well as left knee FPT, ETW and FTW were higher in group I than in group IV. The average values for both right and left knee ETW and FTW were higher than those in group III. The mean values of right and left knee flexor, PT \% BW in group II were higher than those in group IV. These differences were statistically significant $(\mathrm{p} \leq 0.05)$. There were no other statistically significant differences among other groups ( $>0.05$, Tables 3 and 4 ).

\section{Difference between the Two Evaluations}

Within- Groups:

A significant difference was observed in the amount of change in the mean values for left and right knee FPT and left knee flexor PT \% BW. The differences in the values were found to be higher in group II than in group I. In group II (R: IT after SS), the difference observed between the left knee FPT and flexor PT \% BW was higher than that in group III (Ir: IT after DS). These differences were statistically significant $(\mathrm{p} \leq 0.05)$. No other statistically significant differences were found within the groups for other parameters $(\mathrm{p}>0.05$, Tables 3 and 4).

\section{Discussion}

Most athletes are recommended to perform pre-activity DS and post-activity SS. SS may lead to performance degradation when it is performed before activity. To

Table 2. Evaluation of groups according to mean age, height, weight and body mass index

\begin{tabular}{llllll} 
& Group I & Group II & Group III & Group IV & p \\
\hline Age & $22.25 \pm 1.49$ & $20.63 \pm 2.50$ & $24.5 \pm 2.93$ & $23.63 \pm 2.50$ & $0.018^{*}$ \\
Height & $194 \pm 6.95$ & $191.38 \pm 8.31$ & $186.25 \pm 5.18$ & $183.75 \pm 8.94$ & $0.042^{*}$ \\
Weight & $94.88 \pm 13.83$ & $84.75 \pm 8.66$ & $83.88 \pm 10.15$ & $86.38 \pm 11.34$ & 0.204 \\
BMI & $25.11 \pm 2.23$ & $23.12 \pm 1.56$ & $24.14 \pm 2.38$ & $25.48 \pm 1.40$ & 0.091 \\
\hline
\end{tabular}

Data presented are mean values \pm standard deviation, BMI: Body mass index, One-Way ANOVA test,, : $p<0.05$ 
decrease this risk, the following stretching exercises are recommended: resting period following SS, a general warm-up period or DS (13).

There are many studies showing that performance level can vary according to the type of stretching employed. DS improves physical performance, whereas SS improves flexibility. Therefore, when choosing stretching exercises, all the following are considered: i.e., improving flexibility, preventing injuries and improving strength (14).

However, there are also studies that suggest both types of stretching should be performed, in addition to aerobic running, for improving flexibility (15). Some studies have

\section{Table 3. Evaluation of groups according to right and left knee $(60 \% \mathrm{sec})$ extensor and flexor peak torque (Newton meters)} means

\begin{tabular}{|c|c|c|c|c|c|c|}
\hline & & Group I & Group II & Group III & Group IV & $1 p$ \\
\hline \multirow{4}{*}{ R-EPT } & Before & $311 \pm 43.87$ & $286 \pm 51.40$ & $243.38 \pm 31.39$ & $247 \pm 25.82$ & $0.005^{* *}$ \\
\hline & After & $300.5 \pm 51.64$ & $295.63 \pm 52.86$ & $246.88 \pm 33.32$ & $231 \pm 29.20$ & $0.005^{* *}$ \\
\hline & Difference & $-10.5 \pm 21.47$ & $9.63 \pm 19.63$ & $3.5 \pm 21.27$ & $-16 \pm 18.60$ & 0.060 \\
\hline & $2 p$ & 0.209 & 0.208 & 0.656 & $0.045^{*}$ & - \\
\hline \multirow{4}{*}{ R-FPT } & Before & $218.25 \pm 29.70$ & $188.25 \pm 39.43$ & $180.88 \pm 29.81$ & $171.25 \pm 25.28$ & $0.034^{*}$ \\
\hline & After & $217.75 \pm 22.74$ & $210.13 \pm 26.04$ & $187.13 \pm 24.99$ & $178.38 \pm 23.49$ & $0.009 * *$ \\
\hline & Difference & $-0.5 \pm 15.11$ & $21.88 \pm 19.22$ & $6.25 \pm 11.08$ & $7.13 \pm 13.21$ & $0.039 *$ \\
\hline & $2 p$ & 0.928 & $0.015^{*}$ & 0.155 & 0.171 & - \\
\hline \multirow{4}{*}{ L-EPT } & Before & $305.5 \pm 50.53$ & $278.13 \pm 59.90$ & $249.25 \pm 50.64$ & $250.5 \pm 29.95$ & 0.092 \\
\hline & After & $282.25 \pm 42.13$ & $285.75 \pm 60.27$ & $249 \pm 52.09$ & $245.13 \pm 33.27$ & 0.213 \\
\hline & Difference & $-23.25 \pm 31.43$ & $7.63 \pm 26.72$ & $-0.25 \pm 16.08$ & $-5.38 \pm 7.76$ & 0.064 \\
\hline & $2 p$ & 0.075 & 0.446 & 0.966 & 0.091 & - \\
\hline \multirow{4}{*}{ L-FPT } & Before & $206.38 \pm 34.76$ & $174.88 \pm 33.29$ & $174.88 \pm 29.67$ & $155.75 \pm 32.31$ & $0.034^{*}$ \\
\hline & After & $204 \pm 29.84$ & $197 \pm 31.04$ & $173.25 \pm 23.04$ & $165.13 \pm 28.38$ & $0.029 *$ \\
\hline & Difference & $-2.38 \pm 11.81$ & $22.13 \pm 11.95$ & $-1.63 \pm 31.30$ & $9.38 \pm 10.64$ & $0.044^{*}$ \\
\hline & $2 p$ & 0.587 & $0.001^{* *}$ & 0.887 & $0.041^{*}$ & - \\
\hline
\end{tabular}

Data presented are mean values \pm standard deviation, R: Right knee, L: Left knee, EPT: Extensors peak torque, FPT: Flexors peak torque, ${ }^{1}$ One-Way ANOVA test, ${ }^{2}$ Paired sample t-test, ${ }^{*}: p<0.05, * *: p<0.01$

Table 4. Evaluation of groups according to right and left knee $(240 \% \mathrm{~s})$ extensor and flexor total work means

\begin{tabular}{|c|c|c|c|c|c|c|}
\hline & & Group I & Group II & Group III & Group IV & $1 p$ \\
\hline \multirow{4}{*}{ R-ETW } & Before & $2.257 \pm 363.62$ & $1822.38 \pm 367.40$ & $1511.75 \pm 450.97$ & $1628.5 \pm 278.33$ & $0.002 * *$ \\
\hline & After & $2302.25 \pm 371.13$ & $2008.5 \pm 455.45$ & $1679.38 \pm 525.97$ & $1658.88 \pm 267.61$ & $0.013^{*}$ \\
\hline & Difference & $45.25 \pm 184.87$ & $186.13 \pm 214.96$ & $167.63 \pm 168.35$ & $30.38 \pm 117$ & 0.188 \\
\hline & ${ }^{2} p$ & 0.511 & $0.044^{*}$ & $0.026 *$ & 0.487 & - \\
\hline \multirow{4}{*}{ R-FTW } & Before & $2041.25 \pm 327.67$ & $1853.38 \pm 305$ & $1472.5 \pm 307.72$ & $1592.88 \pm 156.65$ & $0.002 * *$ \\
\hline & After & $2140.25 \pm 340.32$ & $1936.13 \pm 456.22$ & $1620.63 \pm 295.7$ & $1706.25 \pm 161.97$ & $0.017^{*}$ \\
\hline & Difference & $99 \pm 192.81$ & $82.75 \pm 244.09$ & $148.13 \pm 358.94$ & $113.38 \pm 103.29$ & 0.956 \\
\hline & ${ }^{2 p}$ & 0.190 & 0.370 & 0.281 & $0.017^{*}$ & - \\
\hline \multirow{4}{*}{ L-ETW } & Before & $2245.5 \pm 329.22$ & $1843.75 \pm 310.63$ & $1670.5 \pm 322.37$ & $1542.13 \pm 235.97$ & $0.001^{* *}$ \\
\hline & After & $2238.5 \pm 339.87$ & $2006 \pm 345.43$ & $1743.13 \pm 256.8$ & $1549.75 \pm 299.63$ & $0.001^{* *}$ \\
\hline & Difference & $-7 \pm 149.59$ & $162.25 \pm 250.17$ & $72.63 \pm 154.60$ & $7.63 \pm 198.11$ & 0.299 \\
\hline & ${ }^{2} p$ & 0.898 & 0.109 & 0.226 & 0.916 & - \\
\hline \multirow{4}{*}{ L-FTW } & Before & $1987.88 \pm 305.23$ & $1740.38 \pm 335.99$ & $1428.88 \pm 233.59$ & $1494.63 \pm 239.33$ & $0.002 * *$ \\
\hline & After & $1966 \pm 417.11$ & $1864.63 \pm 270.45$ & $1548.38 \pm 282.44$ & $1586.88 \pm 290.40$ & $0.035^{*}$ \\
\hline & Difference & $-21.88 \pm 234.67$ & $124.25 \pm 338.32$ & $119.5 \pm 290.91$ & $92.25 \pm 155.75$ & 0.660 \\
\hline & ${ }^{2 p} p$ & 0.800 & 0.333 & 0.283 & 0.138 & - \\
\hline
\end{tabular}

Data presented are mean values \pm standard deviation, R: Right knee, L: Left knee, ETW: Extensors total work, FTW: Flexors total work, ${ }^{1}$ One-Way ANOVA test, ${ }^{2}$ Paired sample t-test, $:$ : $p<0.05, * *: p<0.01$ 
reported that DS increases agility, speed and strength $(8,15)$, whereas some other studies report that SS negatively affects the performance $(2,8,14,16,17)$. Kurt and Firtın (15) suggest that professional athletes may avoid SS before training or competitions to prevent a decrease in anaerobic performance.

Few studies have investigated performance variables, such as endurance (18) and power $(19,20)$, which we examined in our study. The results of this study suggested that DS exercises in well-trained basketball players improved knee extensor and flexor strength and endurance; on the other hand, SS was found to increase extensor strength and knee muscle endurance in less-trained basketball players. These results are consistent with previous studies that did not find any decrease in performance caused by the DS (21). Yamaguchi and Ishii (20) examined 30-s static and DS effect on limb strength. As a result of this study, it was suggested that the 30-s SS did not affect muscular performance, whereas DS led an increase in lower-limb strength (20). Although the results of group II in our study are consistent with the values from the previous study, different results were obtained in group IV. In group IV (Ir: IT after SS) EPT values were found to be statistically significantly lower after SS than after DS. In the same group, PT and PT \% BW values were measured after DS, and they were significantly higher than those measured after SS. Values of the left and right knee flexor strengths (PT and PT\% BW) were measured after DS and they were significantly higher in group II (R: IT after SS) than those measured after SS (right PT, PT \% BW and left PT, PT \% BW).

In our study, differences in the TW (endurance, maintenance of maximal muscle power) were similar among the four groups. Measurements taken after the DS in group II showed a statistically significant increase. In group IV, measurements taken after DS in right flexor (TW and BW values) suggested a significant increase than those after SS. DS is recommended as the primary stretching method before high-speed and force-requiring activities (22). In this type of stretching, athletes perform similar movements that they perform in competitions; thus, they also focus on competitions at the same time (23).

The less-trained group III showed a statistically significant increase in measurements of the right extensor (TW and TW \% BW values) after SS than after DS. Unlike results of the present study, knee flexion and extension maximal performance ( 1 - RM =1- Max repetition) measured $10 \mathrm{~min}$ after SS decreased by $7.3 \%$ and $8.1 \%$, respectively (24).
This decrease in performance may be because of the type of activity following the stretching type and the stretching routine. In recent years, conventions regarding warmup routines have been changed because some types of stretching have been reported to cause performance loss (25). Many athletic teams and individuals have also added DS to their warm-up routines. DS is expected to be superior to SS because DS includes movements similar to those in future competitions (26); however, this has not yet been fully substantiated using scientific research. Many research studies suggest that combining static and DS may have decreased the negative aspects of SS (25).

O'Sullivan et al. (27) examined the short-term effects of warming up with static and DS on hamstring flexibility. Their research included participants with hamstring injuries and a control group. This study suggested that SS increased hamstring flexibility whereas DS had no effect. Therefore, the lack of evaluation on hamstring flexibility is a limitation of our study. Similar research has been conducted with fewer participants, but the sample size (32 people) was another limitation $(20,21,28)$. Further studies should investigate not only the optimal warm-up parameters according to time, intensity and resting intervals but also include dynamic and static-stretching combinations, sports-specificity, environmental conditions and psychological factors.

Thus, we found that SS increases knee extensor strength and endurance in less-trained basketball players; however, DS increases knee flexor strength and endurance.

\section{Conclusion}

Our study results suggest that before competitions, static and DS exercises might affect performance positively in less-trained basketball players. In addition, we found that DS exercises following a warm-up contribute to knee extensor and flexor strength and endurance in well-trained basketball players. Therefore, we suggest that SS should be included in stretching exercise protocols, although with less frequency compared to DS.

\section{Ethics}

Ethics Committee Approval: A quantitative, crosssectional, and prospective study was conducted between 11.12.2013 and 11.06.2014 with the approval of the Ethics Committee of Trakya University Faculty of Medicine (protocol number: TÜTF-GOKAEK 2013/185).

Informed Consent: The written informed consent was obtained from all participants. 
Peer-review: Externally peer-reviewed.

\section{Authorship Contributions}

Concept: C.M.A., F.T., H.K.A., D.D.K., H.T., Design: C.M.A., F.T., H.K.A., D.D.K., H.T., Data Collection or Processing: C.M.A., F.T., Analysis or Interpretation: C.M.A., F.T., H.K.A., D.D.K., H.T., Writing: C.M.A., F.T., H.K.A., D.D.K., H.T.

Conflict of Interest: No conflict of interest was declared by the authors.

Financial Disclosure: The authors declared that this study has received no financial support.

\section{References}

1. Ziv G, Lidor R. Physical attributes, physiological characteristics, on-court performances and nutritional strategies of female and male basketball players. Sports Med 2009;39(7):547-568.

2. Woods K, Bishop P, Jones E. Warm-up and stretching in the prevention of muscular injury. Sports Med 2007;37(12):1089-1099.

3. Thacker SB, Gilchrist J, Stroup DF, Kimsey Jr CD. The impact of stretching on sports injury risk: a systematic review of the literature. Med Sci Sports Exerc 2004;36(3):371-378.

4. Costa EC, dos Santos CM, Prestes J, da Silva J, Knackfuss MI. Acute effect of static stretching on the strength performance of jiu-jitsu athletes in horizontal bench press. Fit Perf J 2009;8(3):212-217.

5. Yamaguchi T, Ishii K, Yamanaka M, Yasuda K. Acute effects of dynamic stretching exercise on power output during concentric dynamic constant external resistance leg extension. J Strength Cons Res 2007;21(4):1238-1244.

6. Olyaei G, Hadian M, Talebian S, Bagheri H, Malmir K, Olyaei M. The effect of muscle fatigue on knee flexor to extensor torque ratios and knee dynamic stability. Arabian Journal for Science and Engineering 2006;31(2):121.

7. Frontera RF LJ. Assessment of Human Muscle Function In: JA $D$, editor. Physical medicine and rehabilitation: principles and practice. 4th ed. Philadelphia: Lippincott Williams \& Wilkins; 2005. p. 140-155.

8. McMillian DJ, Moore JH, Hatler BS, Taylor DC. Dynamic vs. staticstretching warm up: the effect on power and agility performance. J Strength Cond Res 2006;20(3):492-499.

9. Dvir Z. Isokinetics Muscle Testing. New York: Churchill and Livingstone; 1996.

10. Şahin Ö. Rehabilitasyonda izokinetik değerlendirmeler. Cumhuriyet Med J 2010;32(4):386-396.

11. Chan KM, Maffuli N, Korkia P, Raymond CT. Principles and Practice of İsokinetics in Sports Medicine and Rehabilitation. Hong Kong: Williams \& Wilkins; 1996.

12. Gürol B, Yılmaz İ. İzokinetik kuvvet antrenmanı. SPORMETRE Beden Eğitimi ve Spor Bilimleri Dergisi 2013;XI(1):1-11.
13. Peck E, Chomko G, Gaz DV, Farrell AM. The effects of stretching on performance. Curr Sports Med Rep 2014;13(3):179-185.

14. Fletcher IM, Jones B. The effect of different warm-up stretch protocols on 20 metre sprint performance in trained rugby union players. J Strength Cond Res 2004;18(4):885-888.

15. Kurt C, Firtın İ. Comparison of the acute effects of static and dynamic stretching exercises on flexibility, agility and anaerobic performance in professional football players. The Turkish Journal of Physical Medicine and Rehabilitation 2016;62(3):206-213.

16. Shrier I. Does stretching improve performance?: a systematic and critical review of the literature. Clin J Sport Med 2004;14(5):267273.

17. Fletcher IM, Anness R. The acute effects of combined static and dynamic stretch protocols on fifty-metre sprint performance in track-and-field athletes. J Strength Cond Res 2007;21(3):784-787.

18. Franco BL, Signorelli GR, Trajano GS, Costa PB, de Oliveira CG. Acute effects of three different stretching protocols on the Wingate test performance. J Sports Sci Med 2012;11(1):1-7.

19. Marek SM, Cramer JT, Fincher AL, Massey LL, Dangelmaier SM, Purkayastha S, et al. Acute effects of static and proprioceptive neuromuscular facilitation stretching on muscle strength and power output. J Athl Train 2005;40(2):94-103.

20. Yamaguchi T, Ishii K. Effects of static stretching for 30 seconds and dynamic stretching on leg extension power. J Strength Cond Res 2005;19(3):677-683.

21. Samson M, Button DC, Chaouachi A, Behm DG. Effects of dynamic and static stretching within general and activity specific warm-up protocols. J Sports Sci Med 2012;11(2):279-285.

22. Little T, Williams AG. Effects of differential stretching protocols during warm-ups on high-speed motor capacities in professional soccer players. J Strength Cond Res 2006;20(1):203-307.

23. Mann DP, Jones MT. Guidelines to the Implementation of a Dynamic Stretching Program. Strength and Conditioning Journal 1999;21(6):53-55.

24. Kokkonen J, Nelson AG, Cornwell A. Acute muscle stretching inhibits maximal strength performance. Res Q Exerc Sport 1998;69(4):411-415.

25. Behm DG, Chaouachi A. A review of the acute effects of static and dynamic stretching on performance. Eur J Appl Physiol 2011;111(11):2633-2651.

26. Torres EM, Kreamer WJ, Vingren JL, Volek JS, Hatfield DL, Spiering BA, et al. Effects of stretching on upper-body muscular performance. J Strength Cond Res 2008;22(4):1279-1285.

27. O'Sullivan K, Murray E, Sainsbury D. The effect of warm-up, static stretching and dynamic stretching on hamstring flexibility in previously injured subjects. BMC Musculoskelet Disord 2009;10:37.

28. Young WB, Behm DG. Effects of running, static stretching and practice jumps on explosive force production and jumping performance. J Sports Med Phys Fitness 2003;43(1):21-27. 